\title{
BASE NACIONAL COMUM CURRICULAR E A DIVERSIDADE: UM ESTUDO NECESSÁRIO
}

\author{
COMMON CURRICULAR NATIONAL BASE AND DIVERSITY: A
}

STUDY REQUIRED

\author{
BASE NACIONAL COMÚN CURRICULAR Y LA DIVERSIDAD: UN ESTUDIO NECESARIO
}

\author{
Caroline Aparecida Santiago Alibosek ${ }^{1}$ \\ Michelle Fernandes Lima²
}

\begin{abstract}
RESUMO
Este artigo é resultado da pesquisa de conclusão do curso de Pedagogia, buscou-se investigar sobre o conceito de diversidade apresentado na Base Nacional Comum Curricular (BNCC), que se constitui como uma política curricular de caráter normativo destinada para a Educação Infantil, Anos Iniciais e Finais do Ensino Fundamental, com o objetivo de nortear os currículos dos sistemas e redes de ensino das Unidades Federativas. A metodologia utilizada foi a partir do levantamento bibliográfico e documental, com base na versão final da Base Nacional Comum Curricular, além de pesquisas já realizadas que discutem a problemática. 0 presente trabalho está estruturado em três momentos: inicialmente foi contextualizado o processo de elaboração da BNCC, bem como, os posicionamentos de autores e entidades que fomentam essa discussão. Em seguida foi problematizado sobre o conceito de diversidade, buscando identificar como está apresentada nas políticas educacionais bem como nos documentos curriculares norteadores vigentes. No terceiro momento foi realizada uma análise no texto da BNCC, inicialmente para identificar como o termo diversidade está presente no texto do documento e em seguida buscamos verificar em quais contextos o conceito está situado. A pesquisa realizada evidenciou que a questão da diversidade está apresentada de maneira fragmentada e pulverizada, pois o documento apresenta todos os temas que englobam a diversidade de forma ampla no texto. Destaca-se que durante a análise percebe-se um silenciamento das vozes dos autores que trazem a discussão sobre a diversidade e de uma teoria que embasa a versão final da BNCC, desde os aspectos legais até ás áreas de conhecimento estabelecidas para a Educação Infantil, os Anos Iniciais e Finais.
\end{abstract}

PALAVRAS-CHAVE: Base Nacional Comum Curricular. Políticas Curriculares. Educação. Diversidade.

1 Graduada em Pedagogia pela Universidade Estadual do Centro Oeste - Campus Irati. Atuou como estagiária pela Prefeitura Municipal de Irati em 2015. Atuou como bolsista de pedagogia em 2017 no projeto de extensão Núcleo Maria da Penha e em 2018 integrou o Programa Patronato da Comarca de Irati - PR, ambos pela ambos pela Universidade sem Fronteiras - USF pela Universidade Estadual do Centro-Oeste (UNICENTRO). Participou do Programa Institucional de Iniciação Científica (PROIC), na modalidade voluntária. Atualmente é integrante do grupo de pesquisa Estado, Políticas e Gestão da Educação e Mestranda em Educação pela Universidade Estadual do Centro-Oeste na Linha Políticas Educacionais, História e Organização da Educação. Atualmente trabalha como Orientadora Social na Política Municipal da Pessoa Idosa, pela Secretária Municipal de Assistência Social de Irati/PR 2 Professora da Universidade Estadual do Centro Oeste: Campus Irati ( PR), nas disciplinas de Metodologia da Pesquisa em Ciências da Educação e Políticas Educacionais. Professora do Programa de Pós Graduação em Educação. Mestre em fundamentos da educação pela Universidade Estadual de Maringá. Doutora em educação pelo Programa de Pós Graduação em Educação da UFPR. Pós Doutorado pela Universidade Estadual de Ponta Grossa (PPGE/UEPG). Professora do Programa de Pós Graduação em Educação da Universidade Estadual do Centro Oeste. Líder do grupo de pesquisa Estado, Políticas e Gestão da Educação (UNICENTRO/IRATI-PR), Pesquisa nas linhas: Formulação, implementação e avaliação das políticas educacionais (Ed. Básica e Superior); Pesquisa em Políticas Educacionais; Política educacional em Gramsci; História da política educacional (educação superior). Diretora do Setor de Ciências, Humanas, Letras e Artes (SEHLA/l). 


\begin{abstract}
This article is the result of research on the conclusion of a pedagogy course, researched on the concept of diversity at the National Common Curricular Base (BNCC), which is related as a normative curriculum policy for Early Childhood Education, Early and Final Years of Elementary Education, in order to guide the curricula of the teaching systems and networks of the Federative Units. The methodology used was initiated in the bibliographic and documentary survey, based on the final version of the National Common Curricular Base, in addition to research already carried out that discussed a problem. The present work is structured in three moments: the BNCC elaboration process was contextualized, as well as the positions of authors and entities that foster this discussion. Then, it was problematized about the concept of diversity, seeking to identify how it is reading in educational policies, as well as in the current curriculum documents. In the third moment, an analysis was carried out in the text of the BNCC, identifying how the term diversity is present in the text of the document and, next, we seek to verify in which contexts or concept it is located. A survey carried out showed that the issue of diversity is available in a fragmented and fragmented way, as the document presents all the themes that encompass diversity in a broad way in the text. Highlight that during an analysis perceived in a silencing of authors that brings a discussion about diversity and a theory that supports a final version of the BNCC, from the legal aspects to the areas of knowledge studied for Early Childhood Education, the Early and Final Years.
\end{abstract}

KEYWORDS: National Common Curriculum Base. Curricular Policies. Education. Diversity..

\title{
RESUMEN
}

Este artículo es el resultado de una investigación sobre la conclusión de un curso de pedagogía, investigado sobre el concepto de diversidad en la Base Curricular Común Nacional (BNCC), que se relaciona como una política curricular normativa para la educación de la primera infancia, los primeros y últimos años de la educación primaria. , con el fin de orientar los planes de estudio de los sistemas y redes de enseñanza de las Unidades Federativas. La metodología utilizada se inició en la encuesta bibliográfica y documental, basada en la versión final de la Base Curricular Común Nacional, además de la investigación ya realizada que discutió un problema. El presente trabajo se estructura en tres momentos: se contextualizó el proceso de elaboración del BNCC, así como las posiciones de los autores y entidades que fomentan esta discusión. Luego, se problematizó sobre el concepto de diversidad, buscando identificar cómo se lee en las políticas educativas, así como en los documentos curriculares actuales. En el tercer momento, se realizó un análisis en el texto del BNCC, identificando cómo está presente el término diversidad en el texto del documento y, a continuación, buscamos verificar en qué contextos o concepto se ubica. Una encuesta realizada mostró que el tema de la diversidad está disponible de manera fragmentada y fragmentada, ya que el documento presenta todos los temas que abarcan la diversidad de manera amplia en el texto. Resalte eso durante un análisis percibido en un silenciamiento de autores que trae una discusión sobre la diversidad y una teoría que respalda una versión final del BNCC, desde los aspectos legales hasta las áreas de conocimiento estudiadas para la Educación de la Primera Infancia, los Años Tempranos y Finales.

PALABRAS CLAVE: Base Nacional Común Curricular. Políticas Curriculares. Educación. Diversidad

\section{CONSIDERAÇÕE INICIAIS}

A defesa sobre a necessidade de um currículo com uma base nacional comum para os sistemas de ensino da educação básica, não é uma pauta recente na agenda das políticas educacionais brasileiras. Desde a década de 1980, essa discussão vem ganhando destaque a partir dos discursos mundiais que apontam a importância da padronização do currículo e a qualidade da educação. Ressalta-se que tais discussões são permeadas posições divergentes necessidade e viabilidade de um documento com base nacional comum.

A Base Nacional Comum Curricular é uma política pública de Estado que reúne um conjunto de atores individuais e coletivos, ou seja, é uma ação pública que se configura entre atores locais, nacionais, centrais, periféricos, públicos e privados. 0 documento está previsto na 
Constituição Federal de 1988, da Lei de Diretrizes e Bases da Educação Nacional de 1996 (BRASIL, 2012) e em três das metas do Plano Nacional de Educação (PNE) 2014-2024.

Destaca-se que, no artigo 26 da Lei de Diretrizes e Bases da Educação Nacional (LDB), estabelece-se a necessidade de uma base nacional comum "[...] a ser complementada, em cada sistema de ensino e em cada estabelecimento escolar, por uma parte diversificada exigida pelas características regionais e locais da sociedade, da cultura, da economia e dos educandos" (BRASIL, 1996).

Some-se a isto, a Lei 13.005/2014 que aprova o Plano Nacional de Educação (PNE 20142024), que designa como eixo central reforçar as relações de poder que envolvem a BNCC, quando aponta na meta $n^{0} 7$ estratégia 7.1

[...] estabelecer e implantar mediante pactuação interfederativa, diretrizes pedagógicas para a educação básica e a base nacional comum dos currículos, com direitos e objetivos de aprendizagem e desenvolvimento dos alunos (as) para cada ano do ensino fundamental e médio, respeitados a diversidade regional, estadual e local [...] (BRASIL, 2014, Meta nº 7, Estratégia 7.1).

De acordo com as informações apresentadas na plataforma online ${ }^{3}$ instituído pelo Movimento Todos pela Base, a BNCC foi produzida para "ser um documento orientador dos conhecimentos e habilidades essenciais aos quais todos os estudantes brasileiros têm o direito de ter acesso e se apropriar durante sua trajetória na Educação Básica [...]" (MBNC, 2016)4.

Para a compreensão das políticas educacionais atuais frente à atuação do Estado, é fundamental considerar três elementos primordiais: a elaboração, a aprovação e a implementação das políticas. Conforme Bueno (2018), a constituição das políticas educacionais contribui no processo de produção de consensos, pois envolvem interesses, conflitos e contradições de diversos grupos sociais.

A política educacional brasileira adquire novas reconfigurações, devido às determinações dos organismos internacionais e das instituições privadas que produzem discursos hegemônicos frente à agenda educacional, a qual defende com ênfase os interesses da classe dominante.

Segundo Bueno (2018), o processo de produção e organização do documento teve a participação de membros de associações científicas representativas das diversas áreas do

30 documento está disponibilizado no site: http://basenacionalcomum.mec.gov.br/. Acesso: 06 de junho de 2020.

40 documento está disponibilizado no site: http://movimentopelabase.org.br/o-movimento/ Acesso: 06 de junho de 2020. 
conhecimento de Universidades públicas, o Conselho Nacional dos Secretários de Educação CONSED $^{5}$, a União Nacional dos Dirigentes Municipais da Educação - UNDIME6, Ministério da Educação (MEC), Secretarias Estaduais e Municipais de Educação; e fundamentalmente, representantes dos aparelhos privados de hegemonia da classe empresarial que compõem a Movimento pela Base Nacional Comum ${ }^{7}$. Alguns exemplos de setores empresariais que estão à frente das políticas educacionais são Movimento Todos pela Base Nacional Comum, Movimento Todos pela Educação, Itaú, Unibanco, Natura, Fundação Roberto Marinho, Instituto Ayrton Senna, Fundação Lemann, Amigos da Escola, Fundação Victor Civita.

Tais instituições privadas representam setores produtivos da sociedade, como bancos, indústrias, telecomunicações, faculdades privadas e instituições filantrópicas. Macedo (2014, p.1537) destaca que "parceiros privados, na forma de fundações ou não, começavam a se fazer, não apenas presentes - 0 que não seria de estranhar no mundo contemporâneo -, mas insidiosamente presentes", ao mencionar aos projetos ligados à educação.

A partir da relação entre os agentes públicos e privados na construção do currículo nacional, é possível perceber que os interesses foram pensados de um modo hegemônico e elitista. Entretanto, nesse processo, são apresentadas posições contrárias a BNCC por autores e entidades renomadas no campo das políticas educacionais, como por exemplo, a Associação Nacional de Pós-Graduação e Pesquisa em Educação - a ANPEd; a Associação Nacional pela Formação de Profissionais da Educação - ANFOPE; o Fórum de Diretores de Faculdades de Educação - FORUNDIR; e Sindicato Nacional dos Docentes das Instituições de Ensino Superior - ANDES-SN.

Partindo de tais pressupostos, este trabalho buscou investigar sobre o conceito de diversidade apresentado na BNCC, e de que maneira a questão da diversidade está sendo contemplada no documento. Ferreira $(2015$, p.307) aponta que a diversidade refere-se "[...] aos indivíduos ou grupos sociais que são considerados "diferentes" daquilo que a classe dominante define como "padrão", uma referência "certa" que passa a ser naturalizada nas relações sociais".

50 Conselho Nacional de Secretários de Educação - Consed, fundado em 25 de setembro de 1986, é uma associação de direito privado, sem fins lucrativos, que congrega, por intermédio de seus titulares, as Secretarias de Educação Dos Estados e Distritos. Federal. Ver em: http://www.consed.org.br/consed/consed/historia-do-consed, Acesso em $02 / 08 / 2018$

${ }^{6}$ A União Nacional dos Dirigentes Municipais de Educação (Undime) é uma associação civil sem fins lucrativos, fundada em 1986 e com sede em Brasília/ DF. Ver em: https://undime.org.br/institucional/o-que-e-a-undime, Acesso $02 / 08 / 2018$

${ }^{7}$ Esse movimento foi formado por fundações e institutos mantidos pela iniciativa privada, ligados a ideais voltados à criatividade, tecnologia, empreendedorismo e, pelo menos no âmbito do discurso, da educação como ciência aplicada mais do que como práxis política. 
O presente trabalho está estruturado em três momentos: inicialmente é contextualizado 0 processo de elaboração da BNCC bem como os posicionamentos de autores e entidades que fomentam essa discussão. Busca-se trazer a discussão sobre a necessidade ou não de um novo currículo nacional, visto que já existem documentos que embora não tenham caráter obrigatório, possuem a finalidade de orientar os currículos.

No segundo momento do artigo, busca-se discorrer sobre o conceito de diversidade, buscando identificar como é contemplado na legislação educacional brasileira e nos documentos curriculares norteadores, visto que o Brasil é um país multicultural e com diferenças regionais significativas. Por fim, é feita será feita uma análise na BNCC, buscando identificar como o termo diversidade está presente no documento e em quais contextos está localizado. A análise conta com as pesquisas já realizadas sobre essa problemática, bem como com a legislação educacional que contempla a diversidade no contexto escolar.

\section{O processo de elaboração e implementação da Base Nacional Comum Curricular}

Em 2015, o Ministério da Educação (MEC) iniciou os debates obre a necessidade de um currículo nacional, procedendo na construção da Base Nacional Comum Curricular. 0 discurso presente no documento é atrelado aos direitos de todos os indivíduos desenvolverem as mesmas habilidades em todo o território brasileiro, ao longo das etapas da educação básica.

Segundo os dados da plataforma online Movimento pela Base Nacional Comum, a BNCC foi lançada em 16 de setembro de 2015, passando por três meses de consulta pública, coletando mais de 12 milhões de contribuições. Na elaboração da primeira versão do documento, em 2015 , a equipe orientada pelo Ministério da Educação (MEC) foi composta por professores e professoras apontados pelo CONSED e UNDIME, além dos pesquisadores e professores das universidades estaduais e federais.

As contribuições da primeira versão foram direcionadas para a segunda versão, apresentada pelo MEC em maio de 2016, a qual rodou todos os estados em diversas fases por meio de: seminários preparatórios, elaboração inicial, consultas públicas, análises e revisões, audiências públicas até sua homologação final. Segundo Bueno (2018) na segunda versão da Base Nacional, em 2016, sua reestruturação foi realizada por 45 pessoas da comissão de especialistas e 27 coordenadores indicados pelas secretarias estaduais de educação do CONSED. Em relação à presença do UNDIME, foram 14 pessoas da comissão de especialistas e 27 coordenadores indicados pelas presidências estaduais da UNDIME. Sendo assim, o documento 
foi construído por aproximadamente 113 representantes entre especialistas e coordenadores desses dois principais agentes: CONSED e UNDIME (BRASIL, 2016).

Em abril de 2017 foi entregue ao Conselho Nacional de Educação - CNE,a terceira versão do documento, o qual passou por cinco audiências públicas, uma em cada região do país e das contribuições de 22 redatores e pela análise de 56 leitores críticos (BRASIL, 2017). No dia 15 de dezembro, o parecer e o projeto de resolução da terceira versão da BNCC, foram apresentados pelos conselheiros relatores do CNE foram votados em Sessão do Conselho Pleno e aprovados com 20 votos favoráveis e 3 contrários.Logo que em dezembro de 2017 a BNCC foi aprovada pelo Conselho Nacional de Educação e homologada no mesmo mês pelo Ministro da Educação da época, José Mendonça Filho, em Brasília.

Após a aprovação do documento, o ano de 2018 ficou destinado para a implementação em todos os currículos do território brasileiro. Segundo o site "Movimento pela Base Nacional Comum", a implementação do documento começa com a reelaboração dos currículos estaduais e municipais. Além do currículo, as escolas deverão ajustar o Projeto Político Pedagógico à luz do que a BNCC apresenta.

O processo de implementação da BNCC iniciou em 06 de março de 2018, dia esse escolhido pelo MEC, para ser o Dia Nacional de Discussão da BNCC (Dia D), a fim de[...] se debruçar sobre a BNCC para entender por que ela é tão importante, como foi construída, de que forma está estruturada e como vai impactar o dia a dia em sala de aula" (MOVIMENTO PELA BASE NACIONAL COMUM, 2018, s/p).

De acordo com a plataforma online da BNCC, foram elaborados instrumentos para as discussões sobre como os professores, gestores e secretarias devem trabalhar com 0 documento, por meio de diversos vídeos, roteiro de atividades com sugestões de dinâmicas e apresentações, além de vídeos produzidos pelo Movimento Pela Base, intitulada BNCC em profundidade, que procuram auxiliar a compreensão do documento e de como as mudanças irão afetar em cada componente.

Além desses mecanismos de efetivação do documento citados, efetivado um Guia de Implementação ${ }^{8}$ da BNCC, com orientações práticas e sugestões de planos de ação, com 0 objetivo de responder a dúvidas e apoiar os trabalhos que envolvem questões como, por onde começar e como organizar o processo. Um grupo de trabalho composto por técnicos conduziu o processo de elaboração e criação dos materiais deformação sobre a BNCC, juntamente com

\footnotetext{
80 documento está disponibilizado no site: https://implementacaobncc.com.br/wpcontent/uploads/2018/06/guia_de_implementacao_da_bncc_2018.pdf
} 
o apoio técnico do Movimento pela Base e da Comunidade Educativa - CEDAC. Durante a produção, uma equipe formada por 53 coordenadores estaduais da BNCC - um representante da Undime e um do Consed por estado - avaliou a estrutura do Guia e contribuiu para a sua construção.

Na introdução do documento é apresentado que a BNCC,

[...] é um documento de caráter normativo que define o conjunto orgânico e progressivo de aprendizagens essenciais que todos os alunos devem desenvolver ao longo das etapas e modalidades da Educação Básica, de modo a que tenham assegurados seus direitos de aprendizagem e desenvolvimento, em conformidade com o que preceitua 0 Plano Nacional de Educação (PNE). (BRASIL, 2018, p. 7)

Todavia o processo de elaboração da BNCC não é linear, mas contraditório, com diferentes vozes e posicionamentos críticos, que sinalizam que não ocorre um consenso sobre a real necessidade de um currículo com base nacional comum. Logo Silva, Neto e Vicente (2015) afirmam que no campo de lutas pelos sentidos do desenho institucional da democracia dentro de um contexto de elaboração de uma base nacional comum de currículo, o grande desafio:

[...] é, realmente, criar a democracia e 'algo comum' dentro dessa diversidade. Uma ação política fundamental de 'algo comum' é a criação de arenas decisórias ampliadas para as políticas educacionais e, dentro delas, o currículo [...] (SILVA; NETO; VICENTE, 2015, p. 331)

Deste modo é indispensável a seguinte indagação: é possível um documento "comum" curricular abranger todas as diferenças, no que diz respeito ao gênero, aos diferentes contextos, religiões, etnias, culturas, levando-se em conta que essas diferenças estão "sendo constantemente produzidas e reproduzidas através da relação de poder" (SILVA, 2011, p. 88).

As entidades de amplo reconhecimento no campo das políticas educacionais posicionamse contrárias ao processo e a aprovação do documento. Deste modo neste trabalho, são apresentados alguns posicionamentos de tais entidades como: a Associação Nacional de PósGraduação e Pesquisa em Educação - ANPEd; Associação Nacional pela Formação dos Profissionais da Educação - ANFOPE; Fórum Nacional de Diretores de Faculdades; Centro de Educação ou Equivalentes das Universidades Públicas Brasileiras - FORUMDIR; e o Sindicato Nacional dos docentes das Instituições de Ensino Superior - ANDES-SN.

Os posicionamentos podem ser observados de maneira sintética no quadro a seguir:

\begin{tabular}{|c|c|}
\hline & QUADRO 1. POSIÇÕESDAS ENTIDADES REP \\
\hline ENTIDADES & POSICIONAMENTOS CRÍTICOS \\
\hline ANPEd & $\begin{array}{l}\text { - Culmina em um processo antidemocrático, com o alijamento crescente dos diferentes segmentos da } \\
\text { comunidade educacional; } \\
\text { - Retoma a noção de competências que, enquanto concepção conceitual na educação brasileira; }\end{array}$ \\
\hline
\end{tabular}




\begin{tabular}{|c|c|}
\hline & $\begin{array}{l}\text { - Consolida a lógica de responsabilização dos professores pelos resultados, eximindo os sistemas de } \\
\text { ensino e desconsiderando o conjunto de fatores intra e extraescolares que impactam a aprendizagem. }\end{array}$ \\
\hline ANFOPE & $\begin{array}{l}\text { - A padronização curricular que tem como fundamentos o lema "avaliar e punir" estudantes, escolas e } \\
\text { professores; } \\
\text { - A adoção de material didático previamente estabelecido em substituição à formação contínua dos } \\
\text { profissionais da educação; } \\
\text { - O fortalecimento das avaliações nacionais censitárias em larga escala. }\end{array}$ \\
\hline FORUMDIR & $\begin{array}{l}\text { - O documento não espelha a realidade política e social do Brasil; } \\
\text {-Apresenta um texto que fragmenta o currículo pautado por competências; } \\
\text { - Elaborada por metodologia que não assegurou a participação e o diálogo com os sujeitos das } \\
\text { comunidades escolares; } \\
\text { - Exclui o ensino médio no texto e na discussão das audiências públicas, sobretudo depois da } \\
\text { aprovação da Reforma do Ensino Médio. }\end{array}$ \\
\hline ANDES - SN & $\begin{array}{l}\text { - O documento está vinculado a uma proposta de centralização da seleção de conteúdos e sua } \\
\text { uniformização; } \\
\text { - A visa a obtenção da hegemonia neoliberal e neoconservadora, o controle e a mercantilização do } \\
\text { conhecimento, bem como a regulamentação sobre os discursos pedagógicos; } \\
\text {-A BNCC reforça as tendências internacionais de centralização curricular constatadas nos países } \\
\text { principais do capitalismo. }\end{array}$ \\
\hline
\end{tabular}

Fonte: Quadro elaborado pelas autoras, com base nos documentos e manifestos disponíveis pelas entidades.

A partir dos posicionamentos elencados no quadro 1, é possível perceber que as entidades apresentam pontos contrários a BNCC, resultando em retrocessos e esfacelamentos que atingem os sistemas de ensino brasileiro, além dos riscos à democracia, devido ao caráter homogeneizador do documento.

A ANPEd afirma que ocorre a desarticulação da BNCC com o Plano Nacional de Educação - PNE (2014-2024), com as definições das Conferências Nacionais de Educação - CONAE (2010 e 2014), e a ausência de relação com as Diretrizes Curriculares Nacionais, acarretando um descolamento da BNCC frente ao que foi discutido, produzido e materializado nas políticas educacionais no Brasil na última década.

Em virtude dos últimos documentos produzidos com o objetivo de orientar um currículo comum para todas as escolas localizadas em âmbito nacional, Ferreira (2015) aponta que não é necessário um novo documento, uma vez que acontece a ausência de uma política de formação, implantação e monitoramento do vasto sistema educacional, esses documentos viram somente papel impresso.

A partir do que está constituído no artigo 210 da Constituição Federal de 1988, o Estado deve estabelecer conteúdos mínimos para todas as etapas da educação básica, definidos com 60\% aplicados em território nacional e 40\% aplicados de acordo com as especificidades de cada região. A partir disso são formulados alguns documentos que tem como objetivo orientar os currículos. $O$ quadro a seguir apresenta alguns documentos orientadores das publicações oficiais referente ao currículo das escolas brasileiras, 


\begin{tabular}{|c|l|}
\hline \multicolumn{2}{|c|}{ QUADRO 2. DOCUMENTOS CURRICULARES ELABORADOS DE 1995 A 2011 } \\
\hline $\begin{array}{c}\text { ANO DO } \\
\text { NOCUMENTO }\end{array}$ & \\
\hline 1995 & Referencias Curriculares Nacionais para a Educação Infantil. \\
\hline 1997 & Parâmetros Curriculares Nacionais para o Ensino Fundamental. \\
\hline 2011 & Diretrizes Curriculares da Educação Básica. \\
\hline
\end{tabular}

Fonte: Quadro elaborado pelas autoras, de acordo com informações do site do Ministério da Educação

Segundo Ferreira (2015) os documentos oficiais sistematizaram a base curricular comum para que ela fosse implementada pelos estados e municípios no território brasileiro. Entretanto, esse processo não ocorreu de forma ordenada "[...] seja porque os referenciais e diretrizes não são documentos oficiais mandatórios, seja porque não houve por parte do governo federal ações de apoio, monitoramento e avaliação dos desdobramentos dos conteúdos mínimos" (FERREIRA, 2017, p.310)

Sendo assim, Ferreira (2015) defende que diferente da ideia de um "novo" currículo, o maior desafio para o governo federal é tornar a base já existente acessível à diversidade humana, a qual engloba os docentes, estudantes, gestores, funcionários e familiares presentes nas escolas brasileiras.

No próximo item desse artigo será discutido sobre o conceito de diversidade dentro do território brasileiro e como está contemplada na legislação educacional brasileira e nos demais documentos curriculares nacionais.

\section{A diversidade no contexto das políticas educacionais brasileiras}

Discorrer sobre o tema diversidade na conjuntura atual, com um currículo nacional em questão, é um ponto que precisa ser discutido enquanto elemento orientador das práticas pedagógicas que permeiam as diferenças individuais, participativas e inclusivas.

Ao analisar etimologicamente a palavra diversidade, pode-se verificar que, de acordo com o Minidicionário Aurélio (2004), diversidade significa: "1 Qualidade ou condição do que é diverso, diferença, dessemelhança. 2 Divergência, contradição (entre ideias, etc). 3 Multiplicidade de coisas diversas: existência de seres e entidades não idênticos, ou dessemelhantes, oposição.". Desse modo quando se fala sobre diversidade em educação remete-se a ideia de oferecer oportunidades, acesso e permanência a todos os alunos com as mesmas igualdades de condições, respeitando as diferenças.

O conceito de diversidade atualmente está sendo utilizado de modo crescente e continuado nas diversas áreas de conhecimentos e segmentos sociais aplicados em escala 
mundial. Ferreira (2015) compreende que a diversidade é referente "[...] a igualdade inerente a nossa humanidade e a diferença que nos caracteriza como seres históricos, sociais e determinados pela cultura dentro da qual somos inseridos ao nascer e vivemos" (FERREIRA, 2015, p.307).

Nesse viés, Gomes $(2007$, p.19) apresenta que a diversidade é um "[...] fenômeno que atravessa o tempo e o espaço e se torna uma questão cada vez mais séria quanto mais complexas vão se tornando as sociedades". Sendo assim a diversidade está intrinsecamente ligada ao acontecer humano. Segundo Lima (2006, p. 17)

[...] a diversidade é norma da espécie humana: seres humanos são diversos e suas experiências culturais, são únicas em suas personalidades e são também diversos em suas formas de perceber o mundo. Seres humanos apresentam,ainda, diversidade biológica. Algumas dessas diversidades provocam impedimentos de natureza distinta no processo de desenvolvimento das pessoas (as comumente chamadas de "portadoras de necessidades especiais").Como toda forma de diversidade é hoje recebida na escola, há a demanda óbvia, por um currículo que atenda a essa universalidade.

Sobre o conceito de diversidade Gomes (2007, p. 8) aponta que:

[...] a diversidade biológica, no caso dos seres humanos, caracteriza-se pela igualdade em nossa condição de gênero humano que possuem diferenças, a diversidade cultural está representada exatamente nessas diferenças que são modeladas no "processo histórico e cultural e no contexto das relações de poder".

A diversidade é o reflexo da heterogeneidade existente, é uma construção histórica, social, cultural e política das diferenças que ocorre a partir das relações de poder, a qual está presente "[...] na produção de práticas, saberes, valores, linguagens, técnicas artísticas, científicas, representações do mundo, experiências de sociabilidade e de aprendizagem".

Fernandes (2005) aponta que a partir do final de 1970 surgiram movimentos das camadas populares no Brasil, vinculados fortemente com a discussão e à luta sobre gênero e etnia, na procura de uma maior participação e reconhecimento enquanto cidadãos de direitos. A luta pela diversidade, historicamente, tem como base inicial nos movimentos sociais na década de 1980, associada, principalmente, à luta dos movimentos feministas, dos negros e das pessoas com deficiência em busca do reconhecimento legal e político.

Entretanto, ressalta-se que a diversidade abrange todos os sujeitos que por diferentes motivos ocupam posições sociais, econômicas e políticas desiguais frente às demandas das elites dominantes no país. Tal espaço historicamente é ocupado pelas maiorias representadas pelos 
movimentos sociais, principalmente os de caráter identitário ${ }^{9}$ que, a partir dos anos de 1980 contribuem para a entrada de uma visão afirmativa da diversidade e reivindica que a educação considere, nos seus níveis, etapas e modalidades, a relação entre desigualdades e diversidade.

Segundo Gomes (2012) nos últimos dez anos, a pressão histórica desses movimentos sociais aliada a um perfil considerado mais progressista dos setores do Estado brasileiro que causaram mudanças no trato da diversidade no contexto das políticas públicas de caráter universal, despertando, inclusive a implementação de políticas de ações afirmativas.

Contudo Ferreira (2015) aponta que esses grupos, por muito tempo passaram invisíveis dentro das diretrizes internacionais e agendas políticas e econômicas, localizados as margens da sociedade, e que hoje são caracterizados como diversidade humana, passando a ser reconhecidos como sujeito de direitos pelo "novo bloco hegemônico10", organizado pelas elites dominantes que fomentam uma visão de mundo como uma forma natural de entender e operar a sociedade.

Em 2000, inicia-se no território brasileiro um período de políticas públicas sociais e educacionais que visam contemplar os grupos desprivilegiados. Esse momento é marcado pelo crescente uso do termo 'diversidade' no discurso oficial e dentro dos sistemas de ensino. Ferreira (2015) aponta que tal termo se tornou tão importante, que foi incluso em diversos discursos disseminados pelos bancos, clubes, jornais, novelas, pesquisas e eventos acadêmicos, títulos de grupos de pesquisas cadastrados pelos CNPq, passando uma mensagem de relevância e importância dessa discussão.

Segundo Ferreira (2015) o termo diversidade também ganhou força dentro dos movimentos sociais, que representa os diversos grupos com diferentes pautas, os quais tiveram relação direta com as desvantagens, [...] tanto em forma de não acesso aos bens sociais e culturais, ou na forma de exclusão educacional, atingindo a violação do seu direito de participação ou por meio dos preconceitos e discriminações consideradas sutis, explicitas ou escancaradas. (FERREIRA, 2015, p 303).

Portanto, a luta social e política permanecem na base do conceito da diversidade, visto que há muito tempo ocorre uma clara divisão entre os grupos privilegiados e não privilegiados. Atualmente essa divisão é cada vez mais tênue, pois os sujeitos reconhecem seus pares e

\footnotetext{
${ }^{9}$ Algumas representações dos movimentos sociais identitário são os indígenas, negros, quilombolas, feministas, Lésbicas, Gays, Bissexuais, Transexuais e Travestis (LGBTT), povos do campo, pessoas com deficiência, povos e comunidades tradicionais.

${ }^{10}$ Aliança social democrata [...] coligação centrada em três ou quatro grupos que empurram as políticas educativas e sociais para concepção e abordagens conservadoras [os neoliberais, os neoconservadores, os populistas autoritários e a nova classe média profissional e administrativa]. (APPLE, 2001, p. 6).
} 
experiências semelhantes, de tal modo "organizam-se enquanto grupo social, e lutam por reconhecimento de seus direitos. O popular passa a ser referência cultural” (FERREIRA, 2015, p.308).

A questão da diversidade é contemplada nos documentos educacionais de acordo com 0 que está previsto na LDB de 1996, que fundamenta a educação a partir dos princípios de (I) igualdade de condições para o acesso e permanência na escola; (II) liberdade de aprender, ensinar, pesquisar e divulgar a cultura, o pensamento, a arte e o saber; (III) pluralismo de ideias e de concepções pedagógicas; (IV) respeito à liberdade e apreço à tolerância; e (VIII) gestão democrática do ensino público.

Juntamente com a LDB foram designadas normativas e ações voltadas para a questão da diversidade a partir do governo do Fernando Henrique Cardoso (1995-2002). De acordo com Lima (2016), durante esse período as políticas estavam voltadas para a "[...] questão do combate a discriminação, do preconceito e do racismo na esfera pública, entretanto, por seu caráter pontual não respondia ao que os movimentos sociais solicitavam [...]". Entre as ações e normativas, ressalta-se as seguintes:

\begin{tabular}{|c|c|c|}
\hline \multicolumn{3}{|c|}{ QUADRO 3. NORMATIVAS E AÇÕES DESDE 1996 - 2001} \\
\hline ANO & INDICADOR & DESCRITORES \\
\hline 1996 & $\begin{array}{l}\text { Lei de Diretrizes e Bases } \\
\text { da Educação Nacional } \\
\text { 9394/1996 }\end{array}$ & $\begin{array}{l}\text { Artigo de atendimento amplo às demandas de educação no Brasil, alterados } \\
\text { nos governos posteriores por contemplar sem profundidade algumas } \\
\text { especificidades (Educação indígena, Educação de Jovens e Adultos, Relações } \\
\text { Étnico-raciais, dentre outros }\end{array}$ \\
\hline 1996 & $\begin{array}{l}\text { Criação do grupo de } \\
\text { Trabalho Interministerial } \\
\text { para a Valorização da } \\
\text { População Negra }\end{array}$ & $\begin{array}{l}\text { Criação de medidas especiais e temporárias para a eliminação das } \\
\text { desigualdades históricas (raciais, étnicos, religiosos, de gênero, dentre outros) }\end{array}$ \\
\hline 1997 & $\begin{array}{l}\text { Parâmetros Curriculares } \\
\text { Nacionais (Séries Iniciais } \\
\text { do Ensino Fundamental ) }\end{array}$ & $\begin{array}{l}\text { Pluralidade cultural, orientação sexual. Mais aproximado a um planejamento } \\
\text { pedagógico para e não com }\end{array}$ \\
\hline 1998 & Parecer CEB No0/96 & $\begin{array}{l}\text { Diretrizes Curriculares Nacionais para o Ensino Fundamental: meta o ideal de } \\
\text { uma crescente igualdade de direitos humanos entre os cidadãos, baseado no } \\
\text { princípios democráticos }\end{array}$ \\
\hline 1998 & $\begin{array}{l}\text { Parâmetros Curriculares } \\
\text { Nacionais (Série Finais do } \\
\text { Ensino Fundamental ) }\end{array}$ & $\begin{array}{l}\text { Temas transversais (Pluralidade cultural, orientação sexual,, saúde, meio } \\
\text { ambiente): formação para a cidadania em } 4 \text { eixos : Dignidade da pessoa } \\
\text { humana; Igualdade de direitos; Participação e Corresponsabilidade pela vida } \\
\text { social }\end{array}$ \\
\hline 1998 & $\begin{array}{l}\text { Resolução CEB n } n^{0} 3 \text {, de } \\
26 \text { de junho }\end{array}$ & $\begin{array}{l}\text { Diretrizes Nacionais para o Ensino Médio - Art. } 3^{0} \text {, Inciso II: " a Política de } \\
\text { lgualdade, tendo como ponto de partida o reconhecimento dos direitos } \\
\text { humanos e dos deveres e direitos da cidadania..." }\end{array}$ \\
\hline 2000 & $\begin{array}{l}\text { Parâmetros Curriculares } \\
\text { Nacionais (Ensino Médio ) }\end{array}$ & $\begin{array}{l}\text { "[ ...] a política de igualdade deve ser praticada na garantia de igualdade de } \\
\text { oportunidades e de diversidade de tratamentos dos alunos e dos professores } \\
\text { para aprender e aprender a ensinar os conteúdos curriculares". }\end{array}$ \\
\hline 2001 & $\begin{array}{l}\text { Lei } n^{0} 10172 \text {, de } 9 \text { de } \\
\text { janeiro de } 2001\end{array}$ & $\begin{array}{l}\text { Plano Nacional de Educação (2001 - 2010) - Ênfase na "... construção de uma } \\
\text { escola inclusiva, que garanta o atendimento a diversidade humana". }\end{array}$ \\
\hline
\end{tabular}

Fonte: Quadro elaborado pelas autoras, com base nos dados do artigo elaborado por Lima (2016) 
Além das normativas citadas, também existem programas criados pelo SECAD que tem a finalidade de valorizar a riqueza e a diversidade étnica racial. Com base nos dados de Bairros; Bussoleti (2015), alguns programas são apresentados a seguir,

\begin{tabular}{|c|c|}
\hline \multicolumn{2}{|r|}{ QUADRO 4 . PROGRAMAS VOLTADOS PARA A DIVERSIDADE } \\
\hline $\begin{array}{l}\text { Programas voltados para } \\
\text { Educação Especial }\end{array}$ & $\begin{array}{l}\text { Programa Escola Acessível; Salas de Recursos Multifuncionais; - Formação } \\
\text { Continuada de Professores na Educação Especial; BPC na Escola; Acessibilidade } \\
\text { à Educação Superior; Educação Inclusiva: direito à diversidade; Livro Acessivel; } \\
\text { Prolibras. }\end{array}$ \\
\hline $\begin{array}{l}\text { Políticas para Formação } \\
\text { Recursos }\end{array}$ & $\begin{array}{l}\text { Centro de Formação e Recursos; CAP - Centro de Apoio para Atendimento às } \\
\text { Pessoas com Deficiência Visual; CAS - Centros de Capacitação de Profissionais da } \\
\text { Educação e de Atendimento às Pessoas com Surdez; NAAHS - Núcleos de } \\
\text { Atividades de Altas Habilidades/Superdotação; Prêmio Experiências Educacionais } \\
\text { Inclusivas. }\end{array}$ \\
\hline $\begin{array}{l}\text { Políticas para Educação do } \\
\text { Campo, Indígena e relações } \\
\text { Étnico Raciais }\end{array}$ & $\begin{array}{l}\text { Procampo - Apoio à Formação Superior em Licenciatura em Educação do Campo; } \\
\text { Formação Continuada de Professores em Educação do Campo; Projovem Campo - } \\
\text { Saberes da Terra; PNLD Campo; PDDE Campo; PDDE Água; PROLIND - Apoio à } \\
\text { Formação Superior e Licenciaturas Interculturais Indígenas; PET Conexões de } \\
\text { Saberes; UNIAFRO - Ações Afirmativas para a População Negra na Educação } \\
\text { Superior; Formação Continuada de Professores em Educação Quilombola e para } \\
\text { as Relações Etnico-Raciais; Educação Quilombola; Educação Escolar Indígena; } \\
\text { TEES - Territórios Etnoeducacionais; Formação Continuada de Professores em } \\
\text { Educação Escolar Indígena }\end{array}$ \\
\hline $\begin{array}{l}\text { Políticas de educação } \\
\text { Direitos Humanos }\end{array}$ & $\begin{array}{l}\text { Acompanhamento da Frequência Escolar de Crianças e Jovens em Vulnerabilidade; } \\
\text { Condicionalidade em Educação do Programa Bolsa Família - PBF; Formação } \\
\text { Continuada de Professores e Gestores em Educação Ambiental e Educação em } \\
\text { Direitos Humanos; Projeto Escola Que Protege; Prêmio Construindo a Igualdade de } \\
\text { Gênero; Conferência Infanto-Juvenil pelo Meio Ambiente; Comissão de Meio- } \\
\text { Ambiente e Qualidade de Vida (Com Vida). }\end{array}$ \\
\hline $\begin{array}{l}\text { Políticas de Alfabetização e } \\
\text { Educação de Jovens e Adultos }\end{array}$ & $\begin{array}{l}\text { PBA - Programa Brasil Alfabetizado; PNLDEJA - Programa Nacional do Livro } \\
\text { Didático para a Alfabetização de Jovens e Adultos; Concurso Literatura Para Todos. }\end{array}$ \\
\hline Políticas para a Juventude. & Projovem urbano \\
\hline
\end{tabular}

Fonte: Quadro elaborado pelas autoras, com base nos dados do artigo elaborado por Bairros; Bussoleti (2015)

Visto que existem vários documentos, normativas e programas já atuantes voltados para a questão da diversidade humana, é realizada as seguintes indagações: Como a questão da diversidade é contemplada na versão final da BNCC?

\section{A diversidade na Base Nacional Comum Curricular}

O item da Educação Infantil apresentada na BNCC contempla seis direitos de aprendizagem das crianças: conviver, brincar, explorar, participar, expressar-se e conhecerse. Tais direitos estão relacionados às dez competências gerais que regem todo o documento. Enquanto para a modalidade do Ensino Fundamental está organizada em cinco áreas de 
conhecimento ${ }^{11}$, estruturadas por componentes curriculares, para os Anos Iniciais ( $1^{\circ}$ ao $5^{\circ}$ ano) e Anos Finais ( $6^{\circ}$ ao $9^{\circ}$ ano).

Os componentes curriculares da área de Linguagens são organizados em: Língua Portuguesa, Arte, Educação Física e Língua Inglesa. Também apresenta os componentes de Matemática, Ciências da Natureza e Ciências Humanas que abrange Geografia e História e a área de Ensino Religioso. Cada área de conhecimento apresentada estabelece competências ${ }^{12}$ específicas para serem desenvolvidas ao longo dos nove anos do ensino fundamental.

Com o objetivo de identificar o conceito de diversidade apresentado na BNCC realizamos um primeiro filtro minucioso na versão final do documento para identificar quantas vezes o termo diversidade está presente no texto do documento e em seguida buscamos identificar em quais contextos está situado.

Diante disso, foi constatado que o termo diversidade é mencionado 106 vezes. Foi constatado que 17 menções do conceito estão situadas no contexto dos fundamentos e aspectos legais que embasam o documento e 89 vezes os termos estão distribuídos nas áreas de conhecimentos. É possível perceber os resultados nos quadros a seguir,

\section{Fundamentos e Aspectos Legais}

\section{QUADRO 5. CONCEITO DE DIVERSIDADENOS FUNDAMENTOS}

Fonte: Quadro elaborado pelas autoras, de acordo com informações da Base Nacional Comum Curricular

\begin{tabular}{|c|c|c|c|}
\hline \multicolumn{4}{|c|}{ QUADRO 6. CONCEITO DE DIVERSIDADE NASÁREAS DE CONHECIMENTO } \\
\hline $\begin{array}{c}\text { Área das } \\
\text { Linguagens }\end{array}$ & 20 & Área de Ciências da Natureza & - \\
\hline Arte & 3 & Ciências $^{14}$ & 24 \\
\hline Educação física & 2 & Área de Ciências Humanas & - \\
\hline Língua inglesa & 6 & Geografia & 15 \\
\hline Área da Matemática & - & História & 10 \\
\hline Matemática & 2 & Área de Ensino Religioso & 7 \\
\hline
\end{tabular}

Fonte: Quadro elaborado pelas autoras, de acordo com informações da Base Nacional Comum Curricular

Embora o termo diversidade seja muito mencionado ao longo do documento, é possível perceber que está atrelado a diferentes contextos e temas, como a questão da diversidade

\footnotetext{
${ }^{11}$ As áreas estão organizadas de acordo com o parecer CNE/CEB n ${ }^{\circ}$ 11/2010 que tem como finalidade "[...] favorecer a comunicação entre os conhecimentos e saberes dos diferentes componentes curriculares" (BRASIL, 2010, p. 26).

${ }^{12}$ Silva (2008, p. 87) afirma que as competências “[...] utilizam, integram ou mobilizam conhecimentos, isto é, a competência é a expressão da relação entre pensamento e ação". Essa relação apresentada é referente a atividades realizadas cotidianamente, recorrendo aos saberes que foram previamente estabelecidos ou obtidos na própria ação.

${ }^{13}$ Durante o texto introdutório da Área de Linguagem, aparece 20 vezes o termo diversidade vezes dentro das áreas de conhecimento dessa modalidade.

${ }^{14}$ Quando foi realizado o filtro pelo conceito diversidade no documento, na Área da Ciências da Natureza, apareceu 24 vezes o conceito, entretanto 9 vezes era a palavra biodiversidade e 1 sociodiversidade.
} 
cultural, diversidade linguística, diversidade de opiniões, diversidade de conhecimentos, diversidade humana, diversidade de saberes, diversidade biológica, diversidade étnico-cultural, diversidade política, diversidades identitárias, diversidade cultural religiosa, diversidade de vida, diversidade de textos religiosos etc.

A questão da diversidade está apresentada no documento de forma ampla, visto que todas as vezes que aparece o termo refere-se de maneira abrangente a todos os indivíduos e grupos da sociedade. Sendo assim, enfatiza-se que a abrangência da diversidade é extensa e o documento não apresenta um item específico para trabalhar essa temática.

Para discorrer sobre isso, esse momento fará profunda alusão nos resultados que aparecem no Quadro 3, o qual apresenta sobre o conceito dentro dos aspectos legais, que em tese fundamentam o documento. Para a discussão, selecionamos excertos que aparecem o termo diversidade, buscando compreender quais as bases que o documento está fundamentado.

O primeiro excerto ressaltado é referente à $6^{\text {a }}$ competência estabelecida no quadro das competências gerais para a Base Nacional Comum Curricular que aponta a necessidade de,

\begin{abstract}
Valorizar a diversidade de saberes e vivências culturais e apropriar-se de conhecimentos e experiências que the possibilitem entender as relações próprias do mundo do trabalho e fazer escolhas alinhadas ao exercício da cidadania e ao seu projeto de vida, com liberdade, autonomia, consciência crítica e responsabilidade. (BRASIL, 2017, p. 9)
\end{abstract}

Segundo Gomes (2012), o papel da educação e das políticas não é formar pessoas apenas para o mercado de trabalho, para o vestibular ou, para alcançar índices internacionais de alfabetização ou de matematização aplicados pelos sistemas de avaliação de larga escala. Pelo contrário, o foco central dos sistemas de ensino e principalmente do currículo que norteia o que será trabalhado nas aulas, deve estar focado nos alunos como sujeitos sociais, como sujeito críticos e ativos dentro da sociedade.

A BNCC também apresenta que o território brasileiro, é,

[...] caracterizado pela autonomia dos entes federados, acentuada diversidade cultural e profundas desigualdades sociais, os sistemas e redes de ensino devem construir currículos, e as escolas precisam elaborar propostas pedagógicas que considerem as necessidades, as possibilidades e os interesses dos estudantes, assim como suas identidades linguísticas, étnicas e culturais. (BRASIL, 2017, p. 15)

Visto que o documento em seu texto apresenta a compreensão em relação às densas desigualdades sociais impostas e a necessidade de um currículo com singularidades de acordo com as demandas dos alunos, bem como o contexto que está inserido indaga-se a seguinte 
questão: como é possível um currículo com base nacional contemplar todas as demandas de todos os sujeitos dos sistemas de ensino?

A partir do exposto, a diversidade é apresentada em outros documentos e em programas, enfocando os diversos grupos considerados maioria dentro da sociedade. Contudo, acerca da BNCC, percebe-se que não existe nenhum item específico destinado a questão da diversidade, uma vez que se encontra de forma ampla e fragmentada. Segundo Gomes (2007, p. 28) é possível notar que a questão da,

[...] diversidade aparece, porém, não como um dos eixos centrais da orientação curricular, mas, sim, como um tema. E mais: muitas vezes, a diversidade aparece somente como um tema que transversaliza o currículo entendido como pluralidade cultural. A diversidade é vista e reduzida sob a ótica da cultura.

Vale ressaltar que embora os programas, normativas e documentos ainda vigentes representem alguns elementos de avanços no campo das políticas para a diversidade, percebese que na Base Nacional Comum ocorre a ausência dessa discussão, uma vez que apresenta a diversidade de forma pulverizada e sem fundamentação teórica dos autores e entidades que debates sobre 0 assunto.

Outro ponto fundamental destacado a imensa lacuna em relação a fundamentação teórica do documento, uma vez que não " [...] explícita um conjunto de concepção acerca de sua especificidade como: concepção de educação, de mundo e de sociedade. Além disso, não demonstra os fundamentos filosóficos, sociológicos e psicológicos e pedagógicos de ensino" (BUENO, 2018, p. 124). Diante disso, a partir da análise é notável o silenciamento das vozes dos autores que trazem a discussão ou de uma teoria que embasa a versão final da BNCC, desde os aspectos legais até ás áreas de conhecimento estabelecidas para a Educação Infantil, os Anos Iniciais e Finais.

O fato de não ser apresentada uma fundamentação teórica, mostra que a BNCC está sustentada em um grande conjunto de expectativas de aprendizagens e objetivos- objetivos gerais da educação básica, objetivos gerais de cada área do conhecimento, objetivos gerais e específicos dos componentes curriculares - separados por componente curricular e organizados pelos anos de cada etapa da Educação Básica.

É fundamental ressaltar que a BNCC tem caráter normativo, destinado $60 \%$ para 0 conteúdo de base comum aplicado em território nacional e 40\% para a parte diversificada aplicada de acordo com as especificidades de cada região. Entretanto, é necessário indagar: como 
pretende-se trabalhar a parte diversificada, se no documento a questão da diversidade não contempla de maneira absoluta todos os sujeitos e contextos?

\section{Considerações finais}

A diversidade não é apenas diferenças, mas é uma construção histórica, social e cultural das diferenças a qual está ligada às relações de poder, aos processos de colonização e dominação já naturalizados historicamente. Sendo assim a partir do que foi discutido, é possível observar que o processo de elaboração da BNCC é um campo de disputa e diferentes posições intensamente influenciadas, ordenadas por um grupo de indivíduos que compreendem na educação um instrumento de hegemonia que desempenha na sociedade, ou seja, uma função determinante na manutenção de uma sociedade desigual e preconceituosa.

Por meio das leituras e levantamento de dados realizados, pode-se inferir que 0 documento engloba a questão da diversidade de maneira ampla e pulverizada, visto que não há um item específico para discorrer sobre a importância dos diversos grupos que contemplam a diversidade humana, uma vez que já existem documentos vigentes e específicos que buscam atender essa questão, entretanto de caráter não obrigatório.

É fundamental que a escola, conheça as diferenças, valorizando as especificidades e potencialidades de cada um, reconhecendo a importância do ser humano, e em sua base escolar tenha como pauta de luta contra os estereótipos, as atitudes de preconceito e discriminação de qualquer natureza. Desse modo ressalta-se que trabalho com a diversidade emerge como um grande desafio para a educação, a qual deve-se trabalhar a partir de mudanças no currículo e nas adaptações curriculares, na avaliação contínua do trabalho, nos recursos materiais pedagógicos e didáticos, e principalmente em uma concepção educação que promova espaços de diálogos, trocas de ideias e experiências, a fim de reconhecer os alunos e suas diferentes realidades dentro da vasta diversidade presente nas escolas brasileiras.

Ressaltamos que a BNCC apresenta a retirada das menções à identidade de gênero e orientação sexual na BNCC, refletindo seu caráter contrário ao respeito à diversidade $\mathrm{e}$ evidenciando a concessão que o MEC tem feito ao conservadorismo no Brasil. Também apontamos que o documento é fruto de um processo antidemocrático com ampla participação de representantes empresariais e a ausência da participação da comunidade educacional. Além de apresentar uma lógica conteudista com assuntos que não contemplam os debates atuais, à padronização curricular a adoção do material didático previamente estabelecido, o fortalecimento das avaliações nacionais em larga escala, cujos resultados servirão como base para avaliação, 
remuneração e controle do trabalho docente, provocando o enfraquecimento da autonomia dos professores.

\section{REFERÊNCIAS}

ANFOPE. Posição da ANFOPE sobre a BNCC: Repúdio ao processo de elaboração, discussão e aprovação da BNCC e a sua implementação. Brasília. Setembro/2017. Acessado em: 18/0ut. Disponível em: http://ced.ufsc.br/files/2017/09/Nota-ANFOPE-repudia-a-BNCC-.pdf.

ANPED. A Associação Nacional de Pós-Graduação e Pesquisa em Educação (ANPEd) e a Base Nacional Comum Curricular (BNCC). Florianópolis. Outubro/2015. Acesso em: 19/out Disponível em:

http://www.ANPEd.org.br/sites/default/files/images/a_ANPEd_e_a_bncc_versao_final.pdf.

AURÉLIO, 0 mini dicionário da língua portuguesa. Rio de Janeiro, 4ª edição, 2002

BARREIROS, Débora. Base Nacional Comum Curricular (BNCC): sujeitos, movimentos e ações políticas. 38a Reunião Nacional da ANPEd, Maranhão, out/2017. Disponível em:

http://anais.anped.org.br/sites/default/files/arquivos/trabalho_38anped_2017_GT12_227.pdf

BRASIL. Base Nacional Comum Curricular. Brasília, 2015. Disponível em:

http://basenacionalcomum.mec.gov.br/. Acesso em: 19/out.

BRASIL. Constituição (1988). Constituição da República Federativa do Brasil. Brasília, DF:

Senado Federal, 1988.

BRASIL. Lei de Diretrizes e Bases da Educação Nacional. Lei número 9394, 20 de dezembro de 1996.

BRASIL. Lei no 13.005, de 25 de junho de 2014. Aprova o Plano Nacional de Educação (PNE) e dá outras providências. 2. ed. Brasília: Câmara dos Deputados, Edição Câmara, 2015.

Disponível em

$<$ http://bd.camara.gov.br/bd/bitstream/handle/bdcamara/20204/plano_nacional_educacao_20142024_2ed.pdf?sequence=8>.

CONSED. Posicionamento sobre Base Nacional Comum Curricular. Brasília: 2016.

D’VILA, Jaqueline Boeno. As influências dos agentes públicos e privados no processo de elaboração da Base Nacional Comum Curricular. Dissertação (Mestrado) - Universidade Estadual do Centro-Oeste, Programa de Pós-Graduação Stricto Sensu em Educação do Centro de Ciências Humanas, Letras e Artes Guarapuava: Unicentro, 2018.

FERREIRA, Windyz. O conceito de diversidade: Relações de poder e interesses ocultos. Revista Retratos da Escola Brasileira, v.9, n.17, p . 299-319, jul/dez 2015. Disponível em:

file://C:/Users/Carol/Downloads/582-1886-1-PB\%20(1).pdf

http://revistas.pucsp.br/index.php/curriculum/article/viewFile/21666/15916

GOMES, Nilma Lino. "Diversidade cultura, currículo e questão racial. Desafios para a prática pedagógica". In: ABRAMOWICZ, Anete, BARBOSA, Maria de Assunção e SILVÉRIO, Valter 
Roberto (Orgs). Educação como prática da diferença. Campinas: Armazém do Ipê, 2006, p.2140.

GOMES, Nilma Lino. Indagações sobre o currículo - diversidade e currículo. Brasília:

MEC:SEB, 2007. Disponível em:<http://portal.mec.gov.br/seb/arquivos/pdf/Ensfund/indag4.pdf>. Acesso em 20/jul

LIMA, Paulo Gomes. A diversidade nas políticas educacionais no Brasil. Cad. Pes., São Luís, v. 23, n. Especial, set./dez. 2016

MACEDO, Elizabeth. Base nacional comum para currículos: direito de aprendizagem e desenvolvimento para quem. Educação e Sociedade, Campinas, v.36, n 133, p. 891-908, out. Acessado em 17 de outubro de 2016. Disponível em: http://www.scielo.br/pdf/es/v36n133/16784626-es-36-133-00891.pdf

MOEHLECKE, Sabrina. As políticas de diversidade na educação no governo Lula. Cadernos de Pesquisa, v. 39, n. 137, maio/ago. 2009

MOVIMENTO PELA BASE NACIONAL COMUM (MBNC). O movimento Disponível em: $<$ http://movimentopelabase.org.br/o-movimento/>.

SILVA, Ileizi Luciana Fiorelli; NETO, Henrique Fernandes Alves. VICENTE, Daniel Vitor. A proposta da base nacional comum curricular e o debate entre 1988 e 2015. Ciências Sociais Unisinos. São Leopoldo, v. 51, nº 3, p. 330-342, set/dez 2018.

UNDIME. Contribuições da Undime para Base Nacional Comum Curricular. Brasília: 2016. 